DOI: 10.12957/demetra.2018.33348

\title{
Experiências e arranjos familiares no cuidado e práticas corporais em coronariopatas
}

\section{Family experiences and arrangements in the care and bodily practices in coronary patients}

Mayara Cassimira Souza

Jaqueline Teresinha Ferreira'

${ }^{1}$ Universidade Federal do Rio de Janeiro, Instituto de Estudos em Saúde Coletiva. Rio de Janeiro, RJ, Brasil.

Correspondência / Correspondence Mayara Cassimira Souza

E-mail:mayaracassimira.sc@gmail.com

\section{Resumo}

As doenças cardíacas facilitam a compreensão dos significados e interações dos indivíduos com o meio ao qual se inserem, interpretam e vivenciam suas relações. Buscou-se compreender a relação de coronariopatas internados no pré e pós-cirúrgico com o cuidado e as práticas corporais recomendadas e prescritas durante seu adoecimento. Os procedimentos metodológicos embasaram-se na pesquisa qualitativa com método etnográfico, utilizando como técnicas a observação participante e entrevistas etnográficas. A pesquisa foi realizada em um hospital federal de cardiologia da cidade do Rio de Janeiro, no período de setembro de 2015 a fevereiro de 2016. Foram entrevistados 16 pacientes adultos (8 mulheres e 8 homens), com coronariopatia, que se encontravam no período pré-operatório de cirurgia cardíaca e pós-operatório mediato e foi observada a rotina dos mesmos durante a internação. A compreensão das vivências evidenciou que, ao longo do adoecimento desses pacientes, houve recomendações frequentes dos profissionais de saúde quanto à prática de atividade física, em especifico a caminhada; e a alimentação, com base numa dieta restrita em sódio e gordura. No entanto, observou-se que as experiências e arranjos e rearranjos familiares dos pacientes determinam o apoio social para essas práticas corporais e são cruciais no enfrentamento da doença.

Palavras-chave: Coronariopatas. Cuidado. Práticas corporais. Apoio social. 


\section{Abstract}

Heart diseases facilitate the understanding of the meanings and interactions of individuals with the environment in which they live, interpret and experience their relationships. We sought to understand the relationship of coronary patients hospitalized in the pre and post-surgery periods with the care and bodily practices recommended and prescribed during their illness. The methodological procedures were based on qualitative research utilizing the ethnographic method, which uses participant observation and ethnographic interviews as techniques. The study was conducted at a federal cardiology hospital in the city of Rio de Janeiro, from September 2015 to February 2016. Sixteen adult patients ( 8 women and 8 men) with coronary artery disease, who were in the pre-surgery and immediate post-surgery periods of cardiac operation, were interviewed, and their routine was observed during hospitalization. The understanding of the experiences evidenced that, throughout the illness of these patients, there were frequent recommendations from health professionals regarding the practice of physical activity, specifically walking; and a diet restricted in sodium and fat. However, it was observed that the patients' experiences and family arrangements and rearrangements determine the social support for these bodily practices and are crucial in coping with the disease.

Keywords: Coronariopatas. Caution. Bodily practices. Social support.

\section{Introdução}

As estruturas familiares são abordadas em diversos campos do conhecimento, tais como Antropologia, Ciências Sociais, Saúde Coletiva, dentre outras. O núcleo familiar tradicional (pai, mãe e filhos) permanece como referência no imaginário popular, mas várias configurações familiares se fazem presentes no contexto brasileiro. ${ }^{1}$ Na perspectiva de compreender e ampliar os horizontes das configurações familiares percebidas na pesquisa apresentada, conceitua-se família "enquanto um processo de articulação de diferentes trajetórias de vida, que possuem um caminhar conjunto e a vivência de relações íntimas, um processo que se constrói a partir de várias relações, como classe, gênero, etnia e idade". ${ }^{2}$

Com base nesse conceito, é possível compreender como os novos e distintos arranjos e rearranjos familiares que se estabelecem no cotidiano são abordados nos estudos sobre a organização e 
dinâmicas da família brasileira. Constata-se grande diversidade desses arranjos, como por exemplo, famílias extensas com membros diversificados por gênero, etnia e idade; famílias de casal homossexual com filhos; famílias reconstruídas morando no mesmo terreno; famílias sem ligação sanguínea; famílias com mães e pais solteiros, entre outras possibilidades. O olhar para os novos arranjos familiares inviabiliza considerar a família como um modelo único a ser seguido.

É importante, para este trabalho, destacar que "a família como instituição socializadora de seus membros é o espaço de proteção e cuidado onde as pessoas se unem pelo afeto ou por laços de parentesco, independente do arranjo familiar em que se organize.". ${ }^{3}$ Romanelli ${ }^{4}$ enfatiza que os estudos concernentes aos arranjos familiares nos dias atuais são fundamentais para compreender os meios pelos quais as famílias se socializam e transmitem seus valores e normas, uma vez que as formas de sociabilidade vivenciadas pelos membros da família ocorrem de maneira diferenciada, mas complementares.

Assim, lançar um olhar sobre família na atualidade é compreendê-la como um processo social em constante mudança, percebendo os novos arranjos familiares, não se atendo a uma visão estereotipada e predefinida, estabelecidas no processo sócio-histórico, como ideais, normais ou estruturados. ${ }^{5}$

Diante das mudanças e demandas sociais, como tecnologia, globalização, aumento populacional, debates de gênero, entre outros, a família passa por adaptações. As formas de adaptação dizem respeito às necessidades de sobrevivência perante as responsabilidades presentes e vindouras, como por exemplo, condições de cuidado em saúde. ${ }^{6}$

Segundo Carreira \& Rodrigues, ${ }^{7}$ a família é a maior provedora de cuidados em relação a familiares com doenças crônicas; sendo assim, lida diariamente com as fragilidades de idosos acometidos por essa doença. Nesses casos, a família é norteadora no cuidado de seus membros, exercendo papel crucial no manuseio do cuidado familiar no domić́lio.

No contexto das doenças crônicas, os fatores positivos do apoio e das redes sociais nos comportamentos contribuem para seu ajustamento e gerenciamento, assim como na convivência dos pacientes com os serviços e profissionais de saúde, na adesão aos tratamentos, melhora da qualidade de vida, adoção de novos estilos de vida e prevenção dos riscos às doenças. ${ }^{8}$ No entanto, as relações e apoio social dependem do momento vivido pelos atores sociais, da concepção e papel atribuídos ao gênero, do status conjugal, dos membros familiares envolvidos ou ausentes (filhos, netos, pais, etc.), das questões culturais, educacionais e políticas e da forma como os arranjos familiares e o contexto como todo se dinamizam e se estabelecem. ${ }^{9}$ Assim, o apoio social da família é uma fonte de proteção e manutenção da saúde, pois os laços estabelecidos podem fortalecer a saúde através dos significados vivenciados, percebidos e compartilhados nas relações sociais. A rede de apoio familiar favorece a adesão do paciente aos hábitos e comportamentos demandados para enfrentamento da doença, gerando influência positiva no seu cotidiano. ${ }^{10,11}$ 
Em suas diversas formas e intensidade, as redes se constituem de forma ampla e singular. O modo pelo qual as redes de apoio social se estabelecem repercute nas possibilidades de vivências corporais dos pacientes. Após o diagnóstico da doença e do seu enfrentamento, a rede de apoio é crucial para o cuidado e as vivências corporais, refletindo na manutenção e recuperação da doença.

\section{Metodologia}

Os procedimentos metodológicos deste estudo se fundamentam na pesquisa qualitativa com método etnográfico, utilizando como técnicas a observação participante e entrevistas etnográficas. ${ }^{12}$ Esses instrumentos visam fazer a mediação entre marcos teórico-metodológicos e a realidade empírica. ${ }^{13}$ A observação e a entrevista são ferramentas eficazes que permitiram pesquisar o universo escolhido. A utilização de técnicas combinadas buscou suprir as lacunas e tornar mais completa a coleta de informações em campo. ${ }^{14}$

A pesquisadora se apresentou em um hospital federal de cardiologia do Rio de Janeiro para realizar a pesquisa de campo. A proposta foi bem aceita pelos coordenadores de serviço e em seguida tiveram início as observações na enfermaria e nos leitos onde se encontravam os pacientes coronariopatas. Nessa enfermaria, igualmente a receptividade ao trabalho foi boa. Os pacientes a princípio confundiam a pesquisadora com uma profissional de saúde do setor, e aos poucos foi-se esclarecendo sua identidade e interesse. Todos foram muito solícitos em participar das entrevistas, até por que gostavam de partilhar suas histórias, seus receios e suas expectativas.

Durante a pesquisa de campo, o diário de campo foi crucial, pois o tinha para registros pessoais e reflexões, buscando exercitar um olhar sobre o que era estranho e familiar. No entanto, foi crucial buscar perceber o que o campo "pedia", "mostrava", "revelava" para permitir enxergar novas possibilidades de conhecimento do objeto de pesquisa. Isso foi ao encontro do que Dalmolin et al. ${ }^{15}$ enfatizaram sobre o campo nos conduzir a caminhos antes não visualizados, abrindo novos horizontes, encaminhando procedimentos diversificados e mais abrangentes antes não planejados. Assim, as compreensões não se restringiram às falas dos indivíduos e observações pontuais, mas aos sentidos, relações vividas e interações corporais percebidas diariamente nas visitas ao hospital.

Os critérios de seleção dos sujeitos da pesquisa foram: pacientes com doenças coronarianas, adultos, independente do sexo, que se encontravam internados no período pré-operatório de cirurgia cardíaca e pós-operatório, com exceção dos pacientes em estado grave de recuperação. Foram entrevistados somente os pacientes que aceitaram participar do estudo e que concordaram com o Termo de Consentimento Livre e Esclarecido.

A pesquisa foi realizada em um hospital federal de cardiologia da cidade do Rio de Janeiro, de setembro de 2016 a fevereiro de 2017. As observações foram diárias e se direcionaram para a 
rotina dos pacientes. Os locais para a observação foram: os quartos dos leitos, os corredores onde os pacientes deambulam e o hall de entrada dos corredores que dão acesso aos quartos, que possui bancos que favorecem o convívio. Os critérios observados foram: suas práticas corporais nesses espaços, o apoio de seus familiares e amigos para essa e demais relações estabelecidas entre esses e os profissionais presentes em seu dia a dia. Estes locais foram ricos em interações entre pacientes, acompanhantes e, ocasionalmente, profissionais.

Embora as relações com o apoio social do paciente sejam foco deste estudo, as entrevistas ocorreram somente com a presença do paciente nos seus leitos. Foram entrevistados 16 pacientes adultos, entre eles oito mulheres e oito homens, que se encontravam no período pré-operatório de cirurgia cardíaca e pós-operatório. Para além do direcionamento de suas vivências hospitalares, as perguntas se direcionaram às trajetórias individuais dos pacientes perante o enfrentamento da doença.

Para auxiliar no desenvolvimento dessa técnica, as entrevistas foram gravadas mediante autorização dos entrevistados, o que facilitou a condução da entrevista, uma vez que a gravação capta na íntegra e em todas as dimensões as palavras do entrevistado, condicionando a qualidade da escuta e favorecendo uma análise profunda da mesma. ${ }^{14}$ Posteriormente, as gravações foram cuidadosamente transcritas, para análises e interpretações.

Sobre o perfil dos pacientes, a maior parte dos observados estava entre 60 e 75 anos e se depararam com o problema de coração em fase aguda. Residem em diferentes regiões da capital do Rio de Janeiro e de diversas cidades do estado. Quanto ao nível de escolaridade dos pacientes, a maioria estudou até o primário, sendo que apenas dois chegaram ao ensino superior e três eram analfabetos. $\mathrm{O}$ grau de escolaridade foi determinado pelo acesso às escolas, interferências de localidades, condições financeiras e valores familiares. A maior parte declarou não ter tido educação física escolar. Sobre suas ocupações profissionais, a maior parte dos homens entrevistados já haviam se aposentado, mas continuaram a trabalhar até o acometimento da doença. Quanto às mulheres, estas se ocuparam com afazeres domésticos em seu próprio lar ou prestaram serviços a outros lares.

O projeto seguiu os preceitos éticos da Resolução CNS nº 466/2012, sendo submetido e aprovado pelo Comitê de Ética de Pesquisa (CEP) do Instituto de Estudos em Saúde Coletiva da Universidade Federal do Rio de Janeiro, sob parecer número 1.863.965.

\section{Resultados e Discussão}

Durante a pesquisa, foi igualmente perceptível a ausência de um único modelo familiar, mas observou-se prevalência de um núcleo referencial (pai, mãe e filhos) entre casais e viúvos acima de 60 anos. Esse público estabeleceu um único matrimônio - "estamos casados há 42 anos" 
(Mulher, 69 anos, pós-cirúrgico). Os viúvos entrevistados não estabeleceram novos matrimônios e referenciaram sempre o cônjuge falecido - "foi esse ano que eu fui descobri o problema de coração que eu tinha, porque meu, meu marido faleceu em janeiro" (Mulher, 69 anos, pós-cirúrgico). Sarti16 acrescenta a essa discussão de núcleo referencial masculino que, na atualidade, ainda persiste a ideia de autoridade masculina baseada no poder do homem na família e no seu papel de mediador com o mundo externo. A família que não se encontra nesse modelo é considerada frágil perante a sociedade, por não ter a presença no seio familiar um homem que seja o provedor do respeito, da alimentação e da moradia.

Assim, em relação ao público acima dos 60 anos, a referência e origem familiar seguem um modelo padrão, mas as extensões familiares e outras configurações se sucederam ao longo de suas vidas. Em alguns casos, os viúvos foram morar com os filhos - "eu é que moro com eles" (Mulher, 78 anos, pós-cirúrgico); "eu moro com minha filha e os filhos dela” (Homem, 79 anos, pré-cirúrgico) participando como membro da família estabelecida pelos filhos. Outros casais, após criação dos filhos, acolheram e criam netos pequenos - "minha filha trabalha, tem minha neta de 25 anos que também trabalha e tem minha netinha de 3 anos que a gente toma conta" (Homem, 65 anos, pós-cirúrgico).

Evidencia-se também o retorno à casa dos pais de filhos em idade adulta desempregados com ou sem filhos - "ela fica aqui o dia todo, direto, por que ela está sem trabalhar [...]. Ela ajuda muito em casa" (Mulher, 69 anos, pós-cirúrgico). Nessa faixa etária, observou-se configuração de famílias entre irmãos solteiros, uma senhora de 72 anos optou por não casar e cuidar da mãe. Com o falecimento da mãe, cuidou do irmão mais velho, depois o irmão mais novo divorciou-se e passaram a viver os três irmãos juntos, dando e oferecendo suporte social um ao outro.

Presenciam-se, no entanto, arranjos familiares diferentes entre pacientes na faixa etária dos 50 a 60 anos. Pacientes divorciados constituíram família a partir de segundo ou terceiro matrimônio, com ou sem enteados - "oh deixa eu te falar, eu juntei com a menina. Ai separei. [...] aí tudo bem, fiquei um tempo sozinho, ai depois arrumei outra, com essa outra fiquei vinte, vinte cinco anos. Agora separamos, mas minha enteada ainda vai lá em casa” (Homem, 50 anos, pós-cirúrgico). Outros divorciados se distanciaram da família anterior e possuem apenas convívio com a parceira e com seus filhos; há ainda solteiros e divorciados sem vínculos familiares, mas que possuem vínculos de amizade ou de grupos religiosos. Para esses pacientes, os vínculos não sanguíneos são uma fonte de cuidado e proteção, semelhantes aos provindos por parentescos.

Além do mais, o apoio da família no enfrentamento da doença favorece uma proteção, à medida que reduz o isolamento social do paciente e auxilia nas decisões e estratégias de cuidado. ${ }^{17}$ A rede de apoio social foi relatada em diversos momentos pelos pacientes:

Tem muita gente que cuida de mim. Tem meu marido, minha netinha de 13 anos. Entendeu filha?! É meus filhos, minha nora, minhas sobrinhas e vizinhos [...]. Graças a Deus! Muitas pessoas. Eu tive bastantes pessoas para me acompanhar... Meus filhos também forçavam eu a caminhar e foi me segurando (Mulher, 65 anos, pós-cirurgia). 
Minha esposa e meu filho sempre ficaram comigo, minhas filhas também. Cada uma vinha passar a noite. Estava praticamente em casa. Quando conseguia sair era com a filha me levando em algum lugar. Eu mesmo não consigo dirigir mais. Sentia muito cansaço (Homem, 58 anos, pré-cirúrgico).

Apoio total! Até os que não moram lá em casa, é sobrinha, é filhos, todo mundo, amigos, cunhadas. Não fazia nada sozinha, meus filhos me carregavam no colo. Ai eu fico até com raiva, é gente chata "você não pode comer isso, não pode fazer isso", Ih, é chato, minha filha fala "mãe a senhora não pode fazer isso". Mas, graças a Deus minha família é assim, unida (Mulher, 61 anos, pós-cirurgia).

Ainda por cima, assim, lá em casa meus netos é quem me pegava no colo. E vinha assim e me levava, descia e subia. Eu tava achando que tava, assim, muito cansativo pra eles (Homem, 77 anos, pré-cirúrgico).

Não, não foi difícil não (pré-operatório) porque tava tinha minha esposa (Homem, 50 anos, pós-cirúrgico).

Os discursos dos pacientes foram relacionados ao auxílio direto dos familiares, parentes e amigos, com grande valorização da assistência prestada pelos mesmos. O apoio social foi referenciado e correlacionado às estratégias de cuidado para enfrentamento da doença. Os pacientes cardiopatas, antes e após a cirurgia, têm grandes limitações corporais; o cansaço e a falta de ar recorrente impedem a locomoção e manuseamento do próprio corpo. Com isso, os pacientes ficam dependentes de apoio para atividades cotidianas (andar, sentar, se alimentar, pentear, tomar banho). Do mesmo modo, necessitam habituar-se a novas práticas alimentares e, em grande parte, a restrições alimentares, tais como: redução de sódio, de porções e ingestão de gordura, além de não conseguirem elaborar diariamente sua comida.

Os diversos arranjos e rearranjos familiares possuem modos singulares no desenvolvimento de estratégias de cuidado. As recomendações dos profissionais de saúde, sejam elas sobre atividade física ou alimentar, demandam novas organizações diárias que podem repercutir em toda rede de apoio do coronariopata.

Assim, a rede de apoio estabelecida é fundamental para as novas rotinas, que incluem essas adaptações corporais e alimentares, e decisões sobre o tratamento das possíveis práticas a serem adotadas ou não.

\section{O imperativo da doença nos rearranjos familiares}

É importante destacar que, para além dos arranjos familiares diversos, já estabelecidos por vínculos de parentescos ou não, há rearranjos familiares diante do acometimento da doença, da hospitalização e após esta. Elsen et al. ${ }^{18}$ relatam os obstáculos, organizações e reorganizações durante a internação hospitalar e a vida cotidiana da família antes, durante e após, afetando em menor ou maior grau todos os arranjos familiares. Há famílias que conseguem superar as dificuldades da internação e organizam uma estrutura para acompanhar a pessoa. À medida que 
a condição crônica passa por seus momentos de agudização e há maior demanda por cuidados, tornam-se necessários cada vez mais os rearranjos na dinâmica familiar para que se possa proporcionar o atendimento de necessidades essenciais que surgem com a perda da autonomia.

Assim, as discussões sobre redes sociais como recursos de apoio também se fundamentam nos vínculos e na interdependência entre os indivíduos. Os arranjos familiares, com maior prevalência nas famílias de classes populares, se manifestam como recurso protetor, afetivo, informacional e assistencial. $^{19}$

Todavia, Souza ${ }^{20}$ alerta para os conflitos e as ambiguidades também envolvidos nas relações de parentesco e nos arranjos da família. O núcleo familiar, como grupo de convivência, cooperação, divisão de responsabilidades e obrigações entre seus integrantes, permite oferecer e receber apoio e cuidado. No entanto, a falta de vínculos e cuidados familiares ou conflitos pode desfavorecer os benefícios perante a saúde. Isso se percebe no relato de um paciente vivendo sozinho e uma paciente idosa que cuidava dos irmãos idosos:

Não tem ninguém, eu que tenho que fazer. Sou eu mesmo que faço comida. E, fico pegando peso. Não posso, mas não tem ninguém, fico mais sozinho, moro sozinho. E, tem hora que não tem como tem que parar mesmo, o cansaço é demais, parece que vai morrer. Andando aí uns cinquenta metros, tem que parar umas três ou quatro vezes pra poder respirar se não... Tem hora que a gente faz uma coisa e senta, aí eu pego e fico parado um tempão (Homem, 50 anos, pós-cirúrgico).

Minha preocupação era com aquele irmão doente e o outro mais velho para fazer tudo, fazer comida né, essas coisas assim. Mas aí ele faleceu e depois eu precisei vê a cirurgia. Tem o irmão mais velho, me preocupo, ele vem todo dia à tarde, atualmente só ele, não tem mais ninguém que possa vir não (Mulher, 72 anos, pré-cirurgia).

A ausência de relações familiares percebidas no dia a dia dos pacientes solteiros não favorece uma rede maior de apoio social, fazendo com que os mesmos criem e se adequem a estratégias de enfrentamento da doença. A estratégia do paciente de 50 anos foi reduzir o ritmo de execução das tarefas básicas. A senhora de 72 anos espera todas as tardes seu irmão idoso, que sempre comparecia no mesmo horário e fazia companhia a ela durante todo o tempo destinado à visita. Outro paciente solteiro, de 69 anos, que também vive sozinho, quase não recebeu visitas. Após a cirurgia, uma amiga o acompanhou por três dias, depois não mais. A estratégia desse senhor foi permanecer o maior tempo possível no hospital. Ele entrava em conflito com os profissionais, ressaltando e mostrando que partes do seu corpo não estavam bem. Um dia, abordou a pesquisadora e reclamou: "eles tão alegando que eu tenho que ir embora, mas eu já bati o pé dizendo que eu não vou pra lá, eu não vou pra casa assim, eu não vou dar trabalho lá, não".

Estudos relatam que quando o paciente não possui um suporte social (familiares e/ou amigos), tendem a enfrentar maiores dificuldade para lidar com o estresse, comparados àqueles que têm apoio social. Por exemplo, alguns estudos com doenças e mortalidade na terceira idade associam 
esses fatores à ausência de parentes mais próximos, tais como cônjuge e filhos. ${ }^{21}$ Portanto, a rede de apoio familiar representa um elemento fundamental em qualquer fase da vida do individuo. Todos precisam de algum apoio, e a família e a comunidade são locais naturais de proteção e inserção social nas redes informais. Nesses locais de convívio e ajuda mútua, o paciente encontra na rede familiar, na convivência com os vizinhos, suporte para o enfrentamento de dificuldades que encontra em seu cotidiano. ${ }^{22}$

A estrutura familiar como núcleo composta pelo marido, esposa e filhos gerou um padrão de papéis atribuídos à figura da mulher e outros à figura do homem. Esses papéis foram historicamente delegados como condição necessária para ser membro da família. Ao homem foi delegada uma centralidade e autoridade perante os demais membros; à mulher, como esposa e mãe, foram delegadas a subordinação ao chefe da família (homem) e as atribuições de dona de casa. ${ }^{4}$ Para o autor:

[...] a divisão sexual e etária do trabalho é um princípio fundamental que delimita posições e papéis diferenciados de acordo com o gênero e a idade dos componentes da unidade doméstica. Associadas a esse princípio, porém desfrutando de autonomia em relação a ele, as relações de autoridade e poder também se constituem como elementos ordenadores da cena doméstica, definindo para marido e esposa, para pais e filhos posições hierárquicas, direitos e deveres específicos, porém desiguais ${ }^{4}$ (p. 74).

Scott ${ }^{23}$ acrescenta que as diferenciações entre gênero são um produto histórico e de construção social. Essas diferenças biológicas vão sendo apropriadas e naturalizadas pelo social ao longo do tempo, perpassando todas as áreas de relacionamento que envolvem homens, mulheres e poder. Isso revela em alguns estudos a falta de reciprocidade entre os cônjuges em momentos de doenças; as mulheres são confidentes dos maridos, mas não estabelecem a mesma confiança neles. Com isso, os esposos buscam e têm maior retorno de apoio de suas esposas, e por sua vez as mulheres não buscam esse mesmo apoio ou não o encontram. Isso ocorre devido ao sistema hierárquico, que delega e sobrepõe o papel do homem na sociedade. ${ }^{24}$

No hospital, grande parte dos homens acima de 65 anos com direito a acompanhamento tinha apoio e companhia de suas esposas - "a minha 'sereia' vem aí, tamo sempre juntos" (Homem, 65 anos, pré-cirurgia), porém nem todas as mulheres acima de 65 anos gozavam da companhia de seus esposos. Algumas mulheres casadas eram acompanhadas pelas filhas, nora e até irmãs. Nas conversas diárias com as pacientes, elas relatavam estar preocupadas. As filhas, por sua vez, se esforçavam para prestar assistência e cuidado às mães. Uma filha me disse: "Por que, o que acontece?! Nós somos umas filhas protetoras, porque minha mãe é protetora. Aí a gente fica com medo entendeu?!" ressaltando o cuidado minucioso com a mãe.

Percebe-se que também há conflitos entre elas, e que isso se relaciona diretamente ao papel designado "dona de casa" e de cuidadora que é da mãe, e ao medo de que ela venha a perder esse seu posto. ${ }^{25}$ Haviam queixas por parte de ambas; as filhas relatavam empecilhos e reclamações 
vindas da mãe na aceitação da hierarquia e o modo como cuidavam; e as mães lamentavam por não conseguirem ser mantenedoras do cuidado diário prestado a toda a família.

Essas vivências vão ao encontro de estudos nos quais a mulher ocupa o lugar central da mãe como responsável e provedora do cuidado, principalmente em casos de doenças, pois o papel de cuidadora, seja de mãe, filha ou esposa, recai sobre ela. Tradicionalmente, ela detém um perfil de participação mais frequente, mais intenso e mais afetivo. ${ }^{26}$ Mas esse papel feminino atribuído à outra mulher na escala hierárquica e geracional traz repercussões e resistências aos novos papéis atribuídos sobre o cuidado do outrem.

Resumindo, foi observado o papel das filhas nesse processo de cuidado. Dentre os pacientes pesquisados, a relação de cuidado entre mães e filhas foi notória, pois elas são centrais na responsabilização do cuidado nesse momento de adoecimento do familiar. Há uma inversão de papéis: a mãe, de cuidadora, passa a ser cuidada; a filha, de cuidada, passa a ser a cuidadora.

No entanto, isso não é um processo simples. As filhas sentem que assumir o papel de cuidadoras do lar é uma obrigação feminina e de retribuição da proteção, do cuidado ofertado pela mãe à família. Esse papel poderia ser assumido por qualquer familiar, mas são as filhas mulheres que tomam para si esse lugar. Trata-se de uma repetição de papéis de gênero. ${ }^{27}$ No entanto, as mães não aceitam ceder esse lugar. Elas resistem em aceitar as recomendações das filhas, inclusive no tange às atividades físicas. Por exemplo, elas insistem em fazer atividades que não lhe são recomendadas, como por exemplo: subir escadas, levantar pesos, arrastar móveis e caminhar sozinhas.

Estes e outros momentos presenciados da dinâmica familiar revelam que os papéis atribuídos aos membros da família (pai e mãe) implicam todas as fases da vida e que em todas elas há pressões sociais que influenciam nos comportamentos aprovados pelo todo, ou seja, papéis apropriados e esperados em diferentes idades, gêneros, estados civis, etc. ${ }^{28}$ Diante de certas fases etárias e momentos da vida, nesse caso, o de adoecimento, requer adaptações, tais como mudanças no autoconceito e incorporação de novos papéis sociais. ${ }^{29}$

Nota-se, nos depoimentos dos homens sobre suas atividades, igualmente essa mudança de papel. Como relatado acima, os homens se ocuparam integralmente com o trabalho para sustento de suas famílias, parte que sempre ficou fora de casa a maior parte do tempo. Em contrapartida, tanto as esposas que não trabalhavam como as que mantinham trabalho fora de casa exerciam sozinhas as funções domésticas. Com o advento da doença e suas restrições corporais, os homens passam a compor a vida diária do lar e estabelecer novos papéis naquele ambiente. Assim, ocorrem transformações no papel familiar do homem de ser provedor, passando a buscar utilidade em casa, ajudando na arrumação ou fazendo tarefas na rua. Seguem os discursos relacionados a isso.

Ah, varria quintal, colocar comida para os bichos. Esse tipo de coisa (Homem, 65 anos, pós-cirúrgico). 
Saio de casa pra ir naTabuna, pagar uma conta, um aluguel. Ir em Madureira pra comprar uma lâmpada, fio só. Pra mim ir fazer e voltar (Homem, 67 anos, pré-cirúrgico).

Você é uma pessoa ativa o tempo todo, eu era uma pessoa ativa 24 horas, quando não estava trabalhando na rua estava fazendo alguma coisa em casa. Estava ajudando a esposa. Eu cozinho, lavo passo, eu arrumo casa. Morei sozinho muito tempo, então, aprendi fazer tudo isso. Mamãe me ensinou quando eu era jovem essas coisas todas (Homem, 58 pré-cirúrgico).

Erbolato $^{28}$ ressalta que os papéis sociais - as formas de comportamento socialmente determinadas - são reflexos das imposições sociais; no entanto, permitem às pessoas certa flexibilidade em suas manifestações. Depois de estabelecidos novos papéis, são também adotados estilos de interação com os mesmos. Esse anseio dos homens por novas funções vem se opondo a um sentimento de inutilidade relatado por eles.

Durante os diálogos com um senhor de 58 anos à espera de cirurgia, ele se queixava das dificuldades de não conseguir fazer quase nada. Um dia, quando o cumprimentamos, perguntamos como estava se sentindo e ele respondeu: "ai, é um sentimento de inutilidade. Me sinto um inútil, difícil, filha". Começamos a perceber como esse sentimento prevalecia em ambos os gêneros e como isso era relatado nas entrevistas. Seguem-se os depoimentos:

Para mim não foi não, não está sendo fácil. Porque eu gosto de limpar minha casa arrastando os moveis, são manias que você pega, entendeu, eu gosto de fazer minha comida, ai não tem como fazer, ai fui me sentindo um pouco inútil. Agora eu já to aceitando, graças a Deus, no começo não. Foi um tempinho. Eu não ficava chateada com a doença, não ficava, revoltava com a doença, eu não fiquei, ficava triste de não poder fazer as coisas que eu gostava de fazer (Mulher, 61 anos, pós-cirúrgica).

Assim, eu me sinto inútil porque eu não tô conseguindo fazer nada, mesmo assim levanto e lavo louça e as pernas ficam bambeando e da uma impressão de que vai cair, essas coisas assim. assim eu me sinto um inútil, começo a chorar aí ela vem e diz: não deixa que eu faço. Eu respondo que sou um inútil e ela diz: Você não é um inútil, você está doente e precisa se curar (Homem, 58 pré-cirúrgico).

Tô com as telhas quebradas e eu não posso embocar, trocar uma lâmpada. O meu cunhado vem lá em casa e troca. Eu não posso subir em cadeira... eu subo, olho pra lá, quando desço olho pra baixo, e da vontade de cair, ai eu não subo. Muito chato, que não dá pra fazer. Eu fiquei sem força, eu não posso pegar um troço que eu fico com medo, que eu não tenho mais força e cansa. Fico só deitado e comendo. Que não to podendo fazer nada mesmo, e conversando com os meninos deitado (Homem, 67 anos, pré-cirúrgico).

Carvalho \& Cidade $^{30}$ enfatizam que é muito disseminada na sociedade a ideia de que a pessoa que sofre de um problema cardíaco, ou que passou por uma cirurgia, torna-se inútil. Isso se reforça na medida em que a família, por excesso de zelo, pode passar a tratar o paciente como 
um ser incapaz. O excesso de cuidados muitas vezes limita os papéis do paciente, restringindo suas funções. As mulheres não participam mais da organização e zelo da casa, além de abdicarem dos cuidados de membros da família. Os homens deixam de trabalhar fora e muitas vezes não possuem funções diárias dentro de casa, onde suas obrigações eram restritas a consertos, que já não conseguem fazer. No entanto, como descrito anteriormente, os pacientes vão se adaptando e estabelecendo novos papéis, segundo suas possibilidades corporais.

Assim, o contexto familiar representa um elemento fundamental para o apoio e intimidade das diferentes situações com as quais os pacientes se deparam. A família contemporânea vem sofrendo transformações em relação ao surgimento de novos papéis. Esse panorama demonstra que a família, apesar das mudanças frente a diversas situações, continua sendo um local de extrema importância para nutrir afetos e proteção aos pacientes. ${ }^{31}$

\section{A importância da rede de apoio no manejo das práticas corporais do paciente coronariopata}

A rede de apoio é norteadora e imprescindível para a movimentação do paciente e suas possibilidades de vivências corporais no enfrentamento da doença. Percebe-se, nos relatos dos pacientes sobre práticas corporais, que além de se referirem aos locais eleitos ou não para a extensão das mesmas (programas de atividade física desenvolvida pelos Núcleos de Apoio à Saúde da Família, academias populares e ao ar livre, locais privados de ginástica, programas sociais e educação física escolar), eles relatam o incentivo e auxílio de familiares na condução para atividade física e nos locais para isso. Segue os relatos:

Oh com certeza! Tanto que eu tenho uma filha que é personal, que gosta e é profissional de atividade física. Ela ia lá em casa me pegava, botava no carro e me trazia para a academia. Me botava na esteira para caminhar. Ela me carregava porque eu não ia. Ela ia lá e me buscava. Mas isso não foi por muito tempo também porque aí ficou por minha conta, eu melhorei passei a andar sozinho, ficou por minha conta ir e não fui (Homem, 58 pré-cirúrgico).

Não menina eu não conseguia caminhar não. Eles me forçavam (filhos e parentes), mas eu não conseguia caminhar muito não. Entendeu? Custei levantar. Caminha de pouquinho no terreiro. Caminhava aos pouquinhos porque eu não aguentava caminhar muito (Mulher, 65 anos, pós-cirurgia).

Eles mandam eu andar (filhos). Quer me acompanhar mais eu não vou [...] minha filha não faz não, não gosta de nada não, tem academia no prédio, mas ela não vai não, porque não gosta, mas ela quer que eu faça (risos) (Mulher, 78 anos, pós-cirurgia).

Depois do CTI eu caminhava acompanhada, não tinha segurança, ai depois elas (filhas) foram me deixando sair, andar sozinha (Mulher, 61 anos, pós-cirurgia). 
Percebe-se que a família pode respaldar as prescrições médicas sobre atividade física, legitimando-as totalmente. Isso não implica que esses indivíduos tenham como rotina própria a atividade física, que é destinada a quem está doente. Nesse caso, toda a família participa: "Eles mandam fazer (atividade física). Ela (esposa) não vai não, agora os meus meninos vai (academia)" (Homem, 67 anos, pré-cirugico).

Todavia, os familiares também podem rejeitar essa prescrição, ao contrapor as orientações médicas para as atividades físicas, visando à proteção do paciente:

Eles falaram que quando eu chegasse em casa eu podia caminhar um pouquinho pra lá e pra cá. Ai minha filha não achou uma boa. Minha filha achou que não podia né. Porque eu fiquei cinco dias lá no décimo andar e de lá eu fui pra casa. Minha filha falou: não a senhora saiu do CTI cinco dias, não dá pra senhora caminhar não. (Mulher, 68 anos, pós-cirurgia).

Zaparoli e Mattar ${ }^{32}$ salientam que a família ainda é intermediária dos valores que incidem na sociedade, uma vez que ela sempre foi um lugar de harmonia, organização, respeito mútuo e de desenvolvimento de vínculos afetivos entre seus membros. Sarti ${ }^{16}$ ressalta que no espaço familiar se aprende a ordenar e dar sentido às vivências adquiridas, assim como a atribuir significados às relações entre os indivíduos, sendo o lugar privilegiado para elaboração das diversas experiências vividas.

No contexto familiar dos pacientes coronariopatas, os valores e vínculos afetivos podem ser afirmados, restabelecidos ou modificados de acordo com a singularidade e complexidade dos arranjos familiares. Ou seja, a doença pode implicar a reafirmação dos vínculos familiares ou a necessidade de novos arranjos para o cuidado daquele doente. Assim, há necessidade de o doente e a família se adaptarem ou negociarem as prescrições médicas de acordo com esses vínculos. Isso é, quando as prescrições exigem cuidados que não se adequam às relações familiares, há dificuldade para o seguimento daquela prescrição. Isso acontece no caso de dependência para a realização de dietas especiais ou dependência do doente para a realização de tarefas simples, como higiene ou locomoção, por exemplo.

As mudanças na rotina familiar impostas pela doença trazem os impactos dos valores sociais estruturais construídos sobre gênero, idade, papéis sociais e organizações familiares. Por conseguinte, tornam-se necessários rearranjos familiares reformulando os papéis sociais e funcionais, tanto do paciente quanto dos membros cuidadores, para que as estratégias de cuidado possam ir ao encontro das recomendações profissionais. Esses rearranjos dependem das experiências vividas, como solidariedade, dependência, reciprocidade, paciência, superação e união partilhadas ou não no seio familiar. 
Esses valores podem ser conflituosos ou almejados para manuseio das estratégias, a depender de quem representará. Por exemplo: se o esposo precisa executar funções de trabalho doméstico e cuidado com o paciente, este pode aderir ou não, ou parcialmente executá-las. Já se as filhas, irmãs ou outras mulheres próximas tomam frente na execução dessas tarefas, podem representar a perda ou afirmação de papéis sociais e funcionais, no caso de pacientes femininas.

\section{Consideraçóes finais}

Diante dos depoimentos, observam-se aspectos recorrentes nas famílias em relação ao apoio para a prática de atividade física dos pacientes. Em geral, os familiares, sobretudo os filhos, ou mais especificamente filhas, reconhecem a necessidade de o paciente caminhar. Os pacientes relatam que os familiares "mandam" que eles façam, mas questionam o fato de eles não fazerem e inclusive não gostarem também. O outro aspecto percebido é a inciativa dos filhos de acompanhar e conduzir os pais as atividades físicas, assim como as dificuldades pessoais na experiência para adesão à mesma, tais como: insegurança, a falta de vontade e a indisposição física para execução de movimento.

As práticas corporais vivenciadas ou não pelos cardiopatas trazem significados e formam concepções que norteiam o modo pelo qual se relacionaram com as atividades físicas no pré e pósoperatório. Por sua vez, as redes de apoio à saúde influenciam na vivência de práticas corporais dos indivíduos e podem ser determinantes também no enfrentamento do paciente à doença cardíaca, ou seja, a forma como estes vão aderir ou não à atividade física recomendada.

No histórico de atividade física discursado pelo paciente, antes e com o convívio com a doença, as práticas corporais planejadas ou prescritas se deram de modo aleatório, ou seja, sem continuidade. Nos diálogos com os pacientes, é perceptível que aqueles que permaneceram por mais tempo evidenciam como motivo: vínculos de amizade, necessidade de socialização, tempo disponível após criação dos filhos, falecimento do cônjuge e orientação médica - fatores ligados à rede de apoio referida. Portanto, o apoio social vindo da família é crucial para as práticas corporais dos coronariopatas.

\section{Colaboradores}

Souza MC e Ferreira JT participaram em todas as etapas do estudo

Conflito de interesses: As autores declaram não haver conflitos de interesse. 


\section{Referências}

1. Gabardo RM, Junges JR, Selli L. Arranjos familiares e implicações à saúde na visão dos profissionais do Programa Saúde da Família. Rev Saúde Pública. 2009; 43(1):91-97.

2. Freitas RCS. Famílias em transformação: uma realidade atual. Texto Didático, 2001.

3. Santana VC, Oliveira DC, Meira TAV. Novos arranjos familiares: uma breve análise. EFDerportes. com: Revista Digital. [Internet] fev. 2013; 17(177). Disponível em: http://www.efdeportes.com/efd177/ novos-arranjos-familiares-uma-breve-analise.htm

4. Romanelli G. Paternidade em famílias de camadas médias. Estud Pesqui Psicol. 2003; 3(2):79-95.

5. Gomes CP, Silva PA, Pessini MA. A nova configuração familiar: a família contemporânea usuária das políticas públicas. Akrópolis. 2011; 19(2):101-114.

6. Gelinski CRO, Moser L. A família contemporânea terá condições de dar conta das demandas de proteção desenhadas nas políticas sociais?. Anais do XIII ENPESS; 2012; Juiz de Fora.

7. Carreira L, Rodrigues RAP. Dificuldades dos familiares de idoso portadores de doenças crônicas no acesso à Unidade Básica de Saúde. Rev Bras Enferm. 2010; 63(6):933-939.

8. Tilltson TM, Smith MS. Lomis of control, social support and adeherence to the diabetes regimem. Diabetes Educ. 1996; 22(2):133-139.

9. Papalia DE, Olds SW. Desenvolvimento humano. Porto Alegre: Artmed; 2000.

10. Matsukura TS, Marturano EM, Oishi J. O Questionário de Suporte Social (SSQ): estudos da adaptação para o português. Rev Latinoam Enferm. 2002; 10:675-681.

11. Marques EI, Petuco VM, Gonçalves CB. Motivos da não adesão ao tratamento médico prescrito entre os idosos de uma unidade de saúde da família do município de Passo Fundo - RS. Rev Bras Cienc Envelhecimento Hum. 2010; 7(2):267-279.

12. Victoria CG, Knauth DR, Hassen MNA. Pesquisa qualitativa em saúde: uma introdução ao tema. Porto Alegre: Tomo Editorial; 2000.

13. Minayo MCS. O desafio do conhecimento: pesquisa qualitativa em saúde. 9 ed. São Paulo: Hucitec; 2006.

14. Beaud S, Weber F. Guia para a pesquisa de campo: produzir e analisar dados etnográficos. 2 ed. Petrópolis: Vozes; 2014.

15. Dalmolin BM, Lopes SMB, Vasconcellos MPC. A construção metodológica do campo: etnografia, criatividade e sensibilidade na investigação. Saúde e Sociedade. 2002; 11(2):19-34.

16. Sarti CA. A família como ordem simbólica. Psicol USP. 2004; 15(3):11-28.

17. Romanelli G. Família, parentesco e cuidados com doentes. Resumo III Congresso de Saúde Coletiva e I Encontro de Saúde Coletiva do Cone Sul; 16-25 set. 1992; Porto Alegre. p. 73.

18. Elsen I, MArcon SS, Silva MRS. O viver em família e sua interface com a saúde e a doença. Maringá: Eduem; 2002.

19. Canesqui AM, Barsaglini R. Apoio social e saúde: pontos de vista das ciências sociais e humanas. Ciênc Saúde Coletiva. 2012; 17(5):1103-1114. 
20. Souza I. Hostilidade e conflito na lida com a doença mental: a entrada em cena de aspectos negligenciados nos estudos de redes sociais. In: Anais Programa/Resumos $1^{\circ}$ Congresso Brasileiro de Ciências Sociais em Saúde; 7-10 set. 1995; Curitiba. p. 121.

21. Abreu-Rodrigues M, Eliane MFS. A importância do apoio social em pacientes coronarianos. Paidéia. 2008; 18(40):279-288.

22. Lemos N, Medeiros SL. Suporte social ao idoso dependente. In: Freitas EV, Py L, Gorzoni ML, Doll J. Tratado de geriatria e gerontologia. 2 ed. Rio de Janeiro. Guanabara Koogan; 2006. p. 1227-1233.

23. Scott JW. Gender: still a of useful category analysis? Diogenes. 2010; 57(1):7-14.

24. Resende MC. Rede de relações sociais e satisfação com a vida de adultos e idosos. Psicologia para América Latina. fev. 2006; 5: [acesso em: jul. 2009]. Disponível em: http://pepsic.bvsalud.org/scielo. php?script=sci_arttext\&pid=S1870-350X2006000100015

25. Kimura AF. A construção da personagem mãe: considerações teóricas sobre identidade e papel materno. Rev Esc Enferm USP. 1997; 31(2):339-343.

26. Gratão ACM. Sobrecarga e desconforto emocional em cuidadores de idosos. Texto Contexto-Enferm. 2012; 21(2):304-312.

27. Reis LPC, Elaine PR. O fantasma da repetição e a relação mãe/filha. Rev Bras Crescimento Desenvolv Hum. 2006; 16(3):39-52.

28. Erbolato RMPL. Suportes sociais na velhice: uma investigação preliminar. In: Anais do XIV Congresso Brasileiro de Geriatria e Gerontologia e III Encontro Nacional das Ligas de Geriatria e Gerontologia; 2004; Salvador, Bahia. p. 108.

29. Kimmel DC. Adulthood and aging: a interdisciplinary, development view. 3 ed. New York: John Wiley; 1990.

30. Carvalho L, Cidade W. Depressão, impotência e cardiopatia. Revista SOCERJ 2000; 13(3):46-49.

31. Araujo ENP. Intervenções psicogerontológicas na promoção do envelhecimento bem-sucedido. In: Malagutti W, Bergo AMA. Abordagem interdisciplinar do idoso. Rio de Janeiro: Rubio; 2010. p. 57-66.

32. Zapolari SC, Mattar JB. Repesando a família como espelho para a sociedade através de seus valores. Revista Libertas. 2011; 11(1):1-27.

Recebido: 26 de março de 2018

Revisado: 11 de maio de 2018

Aceito: 24 de maio de 2018 